\title{
Acta Neuropathologica and their case reports
}

\author{
Werner Paulus
}

Published online: 11 December 2007

(C) Springer-Verlag 2007

\begin{abstract}
About 20 years ago I considered where to submit my first neuropathology paper, a case report, and concluded that Acta Neuropathologica "is" the appropriate journal. I therefore should be red-faced when admitting that it was only a few years ago (I was already an Editor of this journal) when I realized that "Acta" is not singular, but it represents the plural form of the Latin word actum, meaning file. Acta Neuropathologica stands for something like "Roman Files of Neuropathology". In my defence, I could only say that the Latin word acta does indeed exist and means beach, so that at a time when searching PubMed and submitting papers can be done online and through wireless on the beach, the singular form would be up-to-date. On the other hand, I suggest that the founding editors of this journal could have intended the plural meaning and this is reflected in the title of my editorial.

The Acta Neuropathologica always published case reports. In fact, the very first issue of the journal, which appeared in 1961, included three case reports, one of them on Marchiafava-Bignami syndrome written by Kurt Jellinger, the later managing editor of this journal for almost 30 years. In my own inaugural case report mentioned above, my teacher Jürgen Peiffer and I, hypothesized that the pleomorphic xanthoastrocytoma is not a glial tumor and we argued that the two eminent neuropathologists John Kepes and Lucien Rubinstein, who described this tumor and gave the name for it, must be wrong. In retrospect, I am somewhat surprised that Kurt Jellinger finally accepted our
\end{abstract}

W. Paulus $(\bowtie)$

Institute of Neuropathology, University Hospital,

Domagkstrasse 19, 48149 Münster, Germany

e-mail:paulusw@uni-muenster.de manuscript although the reviews were quite critical. For the neuropathology community as well as the authors, a study on more cases of PXA might have been more useful than a single case report with far-reaching conclusions. For me, the positive consequence of this paper has been a friendship with John Kepes who magnanimously took care of the apparently misled youngster.

However, making friends is not a usual reason for writing up case reports. Why are they written and published then? Case reports can convey new pathological, pathogenetical or clinico-pathological information which are not yet on the record, or they can provide an overview of the literature of a rare disease entity based on a single case. Furthermore, case reports may be educational not only for the reader, but also for the writing author because beginners in the field of scientific writing can acquire knowledge about how, why, and where to publish. In contrast to experimental studies, subjects of which are usually matching the primary interests of only a small minority of readers, case reports are of principle interest to all practicing neuropathologists, as any variant of any disease may be encountered by any neuropathologist at any time. It is my feeling that the case reports are on an average more frequently read than papers on experimental studies and that many neuropathologists love them as readers and authors alike.

What are the types of case reports published in the Acta during the past few years? In general, we prefer case reports in which new pathological evidence obtained in a single case helps to understand a particular disease better. Of course, papers should be well written and excellently illustrated (remember that color figures are published free of charge). Case reports should convey a clear message rather than describe an enigmatic case with several possible diagnostic considerations. It is not sufficient for the educational aspect alone to be fine. We do not publish "we report the 
27th case of XYZ and review the literature" variants of case report and also we do not endorse submitting "gut feeling case papers" ("I have never seen this. Must be rare. We should write it up as a case report"). Not entirely needless to say that the case reports submitted to this journal should deal with neuropathology, at least in part.

Even though case reports are often interesting and well perceived, the prevailing view is that they are not well cited and therefore tend to decrease the journal's impact factor (IF). Given the still ongoing hysteria surrounding the IF, editors have no choice other than trying to increase this magic figure, not primarily because of higher prestige but in the hope of attracting "best" papers. Funding agencies and evaluation committees exert increased pressure on scientists to publish in journals with the highest IF. Consequently, the number of submissions increases with the IF and editors can select from a higher number of papers, ideally leading to increased quality of the accepted papers and usually it further increases the IF. Editors therefore tend to develop implicit or explicit strategies for increasing their journal's IF (and to simultaneously announce that it is the quality that counts, not the IF). One option could be the sheer elimination of case reports. In fact, the more scientific the attitude of a journal, the less probable it includes a case report category (at least under this designation). Likewise, the number of case presentations has decreased at meetings of some national neuropathology societies, presumably because of their "non-scientific" nature. Milder approach is to "hide" them under the letter or correspondence category. The reason is that the yearly IF calculation performed by the Institute for Scientific Information (ISI) counts letters in the numerator (citations) but not in the denominator (published articles), i.e. although letters are usually very rarely cited, they can potentially increase the IF, but they will never decrease it. However, ISI's policy concerning case reports is not really transparent. On the one hand, ISI communicates that it carefully checks each case presentation in order to prevent mere renaming case reports as letters. On the other hand, some journals have managed not to include even their full case reports with abstracts in the denominator. It somehow appears that not only the IF itself but also its calculation is surrounded by magic or affected by politics.

Is it true that case reports are infrequently cited? The latest IF (2006) refers to citations in 2006 of articles published in 2004 and 2005. I screened seven journals, primarily dealing with neuropathology for single case studies published in 2004/2005. I defined them as papers either appearing in the category of case report or dealing with a single case irrespective of the category (original paper, correspondence, neuropathology education, etc.). I identified 189 papers (Table 1). Most of them appeared in "Neuropathology" and "Acta Neuropathologica" (49 papers each), followed by "Clinical Neuropathology" (40 papers). On average, the mean "Case IF" (citations in 2006 divided by publications in 2004 and 2005, each of them restricted to case presentations) was 0.74 . For all journals, the Case IF was $<50 \%$ of the "official" IF (Table 1 ). Papers without abstract were hardly cited with a Case IF of 0.11 as compared to a Case IF of 0.88 for full case reports (with abstract). Furthermore, 112 of 189 papers (59\%) did not receive a single citation in 2006. Even though it is debatable whether the evaluation of case reports by citation statistics makes much sense, the data reflect that the case reports indeed are decreasing the IF of neuropathology journals. On the other hand, occasional case reports have been remarkably cited often. Table 2 shows five papers on single cases that have received more than ten citations at present, indicating that the case reports are not necessarily ignored in the literature. It is hard to find something common in these five case reports but all of them provide important contributions in areas of very active research and clinical interest.

What does that mean for Acta Neuropathologica and their case reports? Not actually too much. In 2007, we have published on an average one case report per issue, in

Table 1 Number of papers on single cases (published in 2004 and 2005) and their citations (2006) in neuropathology journals

\begin{tabular}{|c|c|c|c|c|c|c|c|}
\hline & \multirow[t]{2}{*}{ IF 2006} & \multicolumn{3}{|c|}{ Full case reports } & \multicolumn{3}{|c|}{ Case letters (no abstract) } \\
\hline & & Citations & Number & Case IF & Citations & Number & Case IF \\
\hline J Neuropathol Exp Neurol & 4.37 & 10 & 5 & 2.00 & & & \\
\hline Acta Neuropathol & 2.69 & 58 & 40 & 1.45 & 2 & 9 & 0.22 \\
\hline Neuropathol Appl Neurobiol & 2.68 & 2 & 2 & 1.00 & 1 & 6 & 0.17 \\
\hline Neuropathology & 1.26 & 29 & 35 & 0.83 & 0 & 14 & 0.00 \\
\hline Clin Neuropathol & 1.03 & 24 & 40 & 0.60 & & & \\
\hline Brain Pathol & 5.27 & 8 & 19 & 0.42 & 1 & 6 & 0.17 \\
\hline Folia Neuropathol & 0.98 & 5 & 13 & 0.38 & & & \\
\hline
\end{tabular}

"Case Impact Factors", calculated only for case presentations in analogy to ISI's impact factor, are considerably lower than the "official" overall impact factors 
Table 2 Case reports published in 2004/2005 which have received more than ten citations until now (date of analysis, 30 November 2007)

\begin{tabular}{|c|c|c|c|}
\hline Ref. & Authors & Title & Citations \\
\hline $\begin{array}{l}\text { J Neuropathol Exp } \\
\quad \text { Neurol 63:363-380 }\end{array}$ & Vidal et al. (2004) & $\begin{array}{l}\text { Intracellular ferritin accumulation in neural and extraneural } \\
\text { extraneural tissue characterizes a neurodegenerative } \\
\text { disease associated with a mutation in the ferritin light polypeptide gene }\end{array}$ & 23 \\
\hline $\begin{array}{l}\text { Acta Neuropathol } \\
\text { 109:449-455 }\end{array}$ & Vendrely et al. (2005) & $\begin{array}{l}\text { Fulminant inflammatory leukoencephalopathy associated } \\
\text { with HAART-induced immune restoration in AIDS-related PML }\end{array}$ & 17 \\
\hline $\begin{array}{l}\text { Acta Neuropathol } \\
108: 81-87\end{array}$ & Seilhean et al. (2004) & Amyotrophic lateral sclerosis with neuronal intranuclear protein inclusions & 16 \\
\hline $\begin{array}{l}\text { Clin Neuropathol } \\
\text { 23:183-93 }\end{array}$ & $\begin{array}{l}\text { Mackenzie and Feldman } \\
\quad(2004)\end{array}$ & $\begin{array}{l}\text { Neurofilament inclusion body disease with early onset, frontotemporal } \\
\text { dementia and primary lateral sclerosis }\end{array}$ & 12 \\
\hline $\begin{array}{l}\text { Brain Pathol } \\
14: 290-296\end{array}$ & Leung et al. (2004) & $\begin{array}{l}\text { A pathogenic peripherin gene mutation in a patient with } \\
\text { amyotrophic lateral sclerosis }\end{array}$ & 11 \\
\hline
\end{tabular}

Years of publication are given in parentheses following authors' names

addition to shorter reports occasionally, in the format of case letters, and we will continue to do that. Even though the main focus of this journal is on original papers, we are happy to publish excellent papers on single cases, which report novel findings and help to understand a disease better. We hope that this policy will make the "Acta" an even more interesting journal and that some of our case reports may eventually help to substantially promote the field. 